\title{
A INTEGRAÇÃO LAVOURA PECUÁRIA FLORESTA COMO ALTERNATIVA PARA O DESENVOLVIMENTO SUSTENTÁVEL NO AGRONEGÓCIO ${ }^{1}$
}

\author{
Marina Mendes Gasperini ${ }^{2}$ \\ Magno Federici Gomes ${ }^{3}$
}

RESUMO: A atividade agropecuária possui um grande potencial degradador ao mesmo passo que é de suma importância para a economia mundial. Sabe-se que o crescimento populacional demanda do agronegócio o aumento da produtividade. Todavia, a atividade não pode mais sustentar-se através dos meios de produção atuais. O presente trabalho tem como objetivo analisar a viabilidade da Integração Lavoura Pecuária Floresta (ILPF) como alternativa para o desenvolvimento sustentável do agronegócio. Para tanto, foi utilizado a metodologia teóricadocumental, com raciocínio dedutivo. Ao final, será possível demonstrar a necessidade de Políticas Públicas para que a ILPF seja efetivada como alternativa para o desenvolvimento sustentável.

Palavras-chave: Agronegócio; Integração Lavoura Pecuária Floresta; Desenvolvimento Sustentável; Crise Ambiental; Agropecuária.

\section{THE CROP-LIVESTOCK SYSTEM AS AN ALTERNATIVE FOR SUSTAINABLE DEVELOPMENT IN AGRIBUSINESS}

ABSTRACT: Agricultural activity has a great potential for degradation while it is of paramount importance for the world economy. It is known that population growth demands increased productivity from agribusiness. However, activity can no longer be sustained through current means of production. This paper aims to analyze the feasibility of the Integrated Crop Livestock System as an alternative for the sustainable development of agribusiness. For that, the theoretical-documental methodology was used, with deductive reasoning. In the end, it will be possible to demonstrate the need for Public Policies for the Crop Livestock System to become effective as an alternative for sustainable development.

\footnotetext{
${ }^{1}$ Trabalho financiado pelo Projeto Edital no 03/2019 de Incentivo à Pesquisa da Escola Superior Dom Helder Câmara, resultante dos Grupos de Pesquisas (CNPQ): Regulação Ambiental da Atividade Econômica Sustentável (REGA), NEGESP, Metamorfose Jurídica e CEDIS (FCT-PT).

${ }^{2}$ Mestranda em Direito Ambiental e Desenvolvimento Sustentável pela Escola Superior Dom Helder Câmara. ORCID: http://orcid.org/0000-0001-5129-7244. Currículo Lattes: http://lattes.cnpq.br/6136064112057921. Email: marinagasperini@hotmail.com

${ }^{3}$ Estágio Pós-doutoral em Direito Público e Educação pela Universidade Nova de Lisboa-Portugal (Bolsa CAPES/BEX 3642/07-0). Estágios Pós-doutorais em Direito Civil e Processual Civil, Doutor em Direito e Mestre em Direito Processual, pela Universidad de Deusto-Espanha (Bolsa da Cátedra UNESCO e do Gobierno Vasco-Espanha). Mestre em Educação pela PUC Minas. Professor do Doutorado e Mestrado Acadêmico em Direito Ambiental e Desenvolvimento Sustentável na Escola Superior Dom Helder Câmara. Professor Titular licenciado da Faculdade de Direito Arnaldo Janssen. Advogado Sócio do Escritório Moraes \& Federici Advocacia Associada. Líder do Grupo de Pesquisa: Regulação Ambiental da Atividade Econômica Sustentável (REGA)/CNPQ-BRA e integrante dos grupos: Centro de Investigação \& Desenvolvimento sobre Direito e Sociedade (CEDIS)/FCT-PT, Núcleo de Estudos sobre Gestão de Políticas Públicas (NEGESP)/CNPQ-BRA e Metamorfose Jurídica/CNPQ-BRA. ORCID: http://orcid.org/0000-0002-4711-5310. Currículo Lattes: http://lattes.cnpq.br/1638327245727283. E-mail: magnofederici@gmail.com
} 
Keywords: Agribusiness; Crop-Livestock System; Sustainable Development; Environmetal Crisis; Farming.

\section{INTRODUÇÃO}

As mudanças climáticas são motivo de discussão mundial há décadas. A percepção pela população mundial do potencial destrutivo advindo das mudanças climáticas se iniciou na década de 40 e aumentou com o passar dos anos, até que nos dias de hoje o seu caráter prejudicial se tornou inquestionável.

O derretimento das geleiras, as mudanças drásticas nas características das estações do ano, terremotos, tsunamis, enchentes e desabamentos, são alguns exemplos das consequências da crise ambiental que vivemos. Os gases que contribuem para o efeito estufa são apontados indubitavelmente como responsáveis por grande parte dessas mudanças.

O capitalismo como modelo econômico vigente, tem uma grande participação quando se trata de emissão de gases que contribuem para o efeito estufa. A necessidade da produção desenfreada, o "ter" como valoração social, o consumismo exacerbado, a necessidade de pertencimento através dos bens materiais incitada pelo mercado, fazem parte de um ciclo vicioso, em que a indústria em busca do lucro voraz desenvolve cada vez mais campanhas e produtos que despertam o consumo exacerbado da população, e esta, com ânsia de consumo, acaba alimentando a indústria cada vez mais. Ademais, o principal problema advém do uso pelas indústrias de fontes energéticas como os combustíveis fósseis, grandes vilões do meio ambiente.

Apesar da grande contribuição da indústria para a degradação ambiental, ela ainda é responsável pelo desenvolvimento mundial. Dessa forma, não há razoabilidade no que tange ao encerramento das atividades agropecuárias, como exemplo, para a preservação ambiental. O desafio das últimas décadas foi justamente pensar em como seria possível aliar o desenvolvimento econômico com a preservação do meio ambiente. Surgiu, em 1987, no relatório Our Common Future, o termo que conhecemos como Desenvolvimento Sustentável.

O desenvolvimento sustentável consiste no desenvolvimento econômico e social, aliado ao meio ambiente. Alguns doutrinadores defendem que existem três dimensões do desenvolvimento sustentável, que serão tratados no capítulo 01 do presente trabalho.

No Brasil, o agronegócio representa grande parte do Produto Interno Bruto brasileiro (PIB) mas em contrapartida é uma atividade altamente degradante, que fere o meio ambiente. 


\section{A INTEGRAÇÃO LAVOURA PECUÁRIA FLORESTA COMO ALTERNATIVA PARA O DESENVOLVIMENTO SUSTENTÁVEL NO AGRONEGÓCIO}

Na pecuária, como exemplo, a emissão de Carbono e Metano é significativa. Do outro lado, o aumento exponencial da população mundial e a demanda constante pela produção de alimentos fazem com que o Brasil seja um dos principais candidatos a abastecer a demanda mundial por alimentos, tendo em vista a sua extensão territorial, clima tropical e grande capacidade produtiva, dado ao constante crescimento tecnológico no campo. Entretanto, um dos grandes desafios é fazer com que a atividade se desenvolva sustentavelmente.

No sentido da agricultura sustentável e dos compromissos firmados pelo Brasil para a redução da emissão de gases que contribuem para o efeito estufa, foi criado o Decreto $\mathrm{n}^{\circ}$ 9.578, de 22 de novembro de 2018, que dispõe acerca do Fundo Nacional de Mudança do Clima de que trata a Lei $\mathrm{n}^{\mathrm{o}} 12.114$, de 9 de dezembro de 2009, e a Política Nacional sobre Mudança do Clima, de que trata a Lei n ${ }^{\circ}$ 12.187, de 29 de dezembro de 2009.

Dessa forma, institui o Plano Setorial de Mitigação e de Adaptação às Mudanças Climáticas para a Consolidação de uma Economia de Baixa Emissão de Carbono na Agricultura, o qual estabelece a Integração Lavoura Pecuária Floresta (ILPF) como uma excelente alternativa para a redução da emissão de gases que contribuem para o efeito estufa, sendo esse o tema deste artigo.

Por sua vez, os problemas que se pretende resolver são: a ILPF é um instrumento de efetivação do desenvolvimento sustentável? Se afirmativo, quais são os óbices para sua efetiva implementação?

Dessa forma, o presente trabalho tem como objetivo demonstrar a viabilidade do sistema de ILPF como alternativa para o desenvolvimento sustentável na agropecuária.

A pesquisa se justifica uma vez que a economia brasileira, em sua grande parte, é impulsionada pelo agronegócio. O setor também é um dos maiores responsáveis pela degradação ambiental, faz-se necessário estudar alternativas para que seja possível aliar o crescimento do setor a preservação ambiental.

Para tanto, o presente artigo utilizou da metodologia teórica-documental, com raciocínio dedutivo. O presente trabalho adota como marcos teóricos as obras de Balbino (2011), Gomes e Ferreira $(2017 ; 2018)$.

$\mathrm{Na}$ primeira parte da pesquisa será analisado do surgimento e das dimensões do desenvolvimento sustentável através da análise e estudo de doutrina. Em seguida, será estudado o Plano de Agricultura de Baixo Carbono (Plano ABC), ao acontecimentos que levaram a sua implementação e o seu desenvolvimento no Brasil. Na terceira parte tratar-se-á do Sistema de Integração Lavoura Pecuária Floresta (ILPF) como parte do Plano de CONPEDI LAW REVIEW | EVENTO VIRTUAL | v. 6 | n. 1 | p. 01 - 18 | JAN - DEZ | 2020 
Agricultura de Baixa Emissão de Carbono, os seus conceitos de implementação, bem como os benefícios e malefícios inerentes ao sistema. Para que, ao final, seja possível determinar se a Integração Lavoura Pecuária Floresta pode ser uma alternativa para o Desenvolvimento Sustentável no Agronegócio.

\section{CRISE AMBIENTAL E DESENVOLVIMENTO SUSTENTÁVEL}

A percepção da humanidade acerca da crise ambiental e das mudanças climáticas cresceu ao longo dos séculos, acontecimentos como as chuvas ácidas, modificações na qualidade do ar e água, voltaram a atenção para as questões ambientais. "A maior preocupação com o meio ambiente se deu basicamente a partir de meados dos anos de 1970 quando a população mundial passou a observar severas modificações na qualidade do ar, da água e do solo, em razão da forte e maciça degradação ambiental bancada." (GOMES; FERREIRA, 2018, p. 158). Outro marco que denunciou os efeitos de uso de pesticidas e inseticidas químicos, foi a publicação do livro Silent Spring de Rachel Carson.

Todos esses acontecimentos culminaram na aprovação da Conferência de Estocolmo em 1972. De um lado, os países desenvolvidos se preocupavam com a preservação do meio ambiente, do outro, os países não desenvolvidos se preocupavam com o atraso que a preservação ambiental poderia trazer para o seu desenvolvimento. Após Estocolmo, relatórios como o Only One Earth, Limits to Growth marcaram a discussão acerca da preocupação com a preservação do meio ambiente.

Apenas em 1983, na Comissão Mundial Sobre o Meio Ambiente e Desenvolvimento, liderada por Gro Harlem Bruntland, foi publicado um relatório conhecido como Nosso Futuro Comum (Our Common Future), que pela primeira vez trouxe o conceito de Desenvolvimento Sustentável:

O desenvolvimento sustentável é o desenvolvimento que encontra as necessidades atuais sem comprometer a habilidade das futuras gerações de atender suas próprias necessidades.[...] Um mundo onde a pobreza e a desigualdade são endêmicas estará sempre propenso à crises ecológicas, entre outras...O desenvolvimento sustentável requer que as sociedades atendam às necessidades humanas tanto pelo aumento do potencial produtivo como pela garantia de oportunidades iguais para todos.[...]Muitos de nós vivemos além dos recursos ecológicos, por exemplo, em nossos padrões de consumo de energia... No mínimo, o desenvolvimento sustentável não deve pôr em risco os sistemas naturais que sustentam a vida na Terra: a atmosfera, as águas, os solos e os seres vivos, na sua essência, o 
desenvolvimento sustentável é um processo de mudança no qual a exploração dos recursos, o direcionamento dos investimentos, a orientação do desenvolvimento tecnológico e a mudança institucional estão em harmonia e reforçam o atual e futuro potencial para satisfazer as aspirações e necessidades humanas (COMISSÃO MUNDIAL SOBRE MEIO AMBIENTE E DESENVOLVIMENTO, 1991, p. 46).

Ao se seguir a tendência internacional, a Constituição Federal de 1988 consagra o direito ao meio ambiente protegido e ecologicamente equilibrado como um direito fundamental. Por se tratar de bem coletivo, de uso difuso, intergeracional, possui uma proteção especial. Acerca do tema, Bölter e Derani asseveram:

A Constituição Federal permitiu avanços significativos na perspectiva de positivação das normas jurídicas ambientais e na normatização sobre desenvolvimento. $\mathrm{O}$ texto constitucional é expressamente um texto garantidor de direitos, em uma perspectiva de proteção e preservação ambiental. Dois elementos indicam esses avanços: primeiro, a garantia de um meio ambiente ecologicamente equilibrado, assegurado para as presentes e as futuras gerações (art.225 CF/88); e, segundo, o princípio deque o desenvolvimento deve ser entendido sob a ótica do desenvolvimento sustentável e da proteção ao meio ambiente (art. 170 da CF/88) (BÖLTER, DERANI, 2018, p. 213).

Em 1992, na Conferência das Nações Unidas para o Meio Ambiente e Desenvolvimento no Rio de Janeiro, o compromisso com o meio ambiente e a necessidade de crescimento através do desenvolvimento sustentável foi apenas ratificada, através da criação da Agenda 21, que consistia em um plano de ação adotado pelos países para tentar realizar a mudança do modelo econômico atual. Os eventos seguintes, como o Rio +10 e Rio +20 ocorreram sem maiores determinações.

Em 2015, a Cúpula de Desenvolvimento Sustentável, que ocorreu em Nova York, definiu novos objetivos do desenvolvimento sustentável, com prazo para 2030. Foram criados 17 objetivos globais, que através de um esforço conjunto de todos os governos, serão essenciais para a implementação do desenvolvimento sustentável ${ }^{4}$.

\footnotetext{
${ }^{4}$ Objetivo 1. Acabar com a pobreza em todas as suas formas, em todos os lugares. Objetivo 2. Acabar com a fome, alcançar a segurança alimentar e melhoria da nutrição e promover a agricultura sustentável. Objetivo 3. Assegurar uma vida saudável e promover o bem-estar para todos, em todas as idades. Objetivo 4. Assegurar a educação inclusiva e equitativa e de qualidade, e promover oportunidades de aprendizagem ao longo da vida para todos. Objetivo 5. Alcançar a igualdade de gênero e empoderar todas as mulheres e meninas. Objetivo 6. Assegurar a disponibilidade e gestão sustentável da água e saneamento para todos. Objetivo 7. Assegurar o acesso confiável, sustentável, moderno e a preço acessível à energia para todos. Objetivo 8. Promover o crescimento econômico sustentado, inclusivo e sustentável, emprego pleno e produtivo e trabalho decente para todos. Objetivo 9. Construir infraestruturas resilientes, promover a industrialização inclusiva e sustentável e fomentar a inovação. Objetivo 10. Reduzir a desigualdade dentro dos países e entre eles. Objetivo 11. Tornar as cidades e os assentamentos humanos inclusivos, seguros, resilientes e sustentáveis. Objetivo 12. Assegurar padrões de produção e de consumo sustentáveis. Objetivo 13. Tomar medidas urgentes para combater a mudança do clima e seus impactos. Objetivo 14. Conservação e uso sustentável dos oceanos, dos mares e dos recursos CONPEDI LAW REVIEW | EVENTO VIRTUAL | v. 6 | n. 1 | p. 01 - 18 | JAN - DEZ | 2020 
Segundo Gomes e Ferreira (2018), é possível observar as dimensões da sustentabilidade através dos objetivos para o desenvolvimento sustentável, sendo forçoso reconhecer na sua visão, no mínimo 5 dimensões da sustentabilidade, quais sejam, social, ambiental, econômica, ética e jurídico-política. Com isso:

\begin{abstract}
Verifica-se que os objetivos determinados pelo PNUD remontam a uma união de conceitos determinantes para o pleno desenvolvimento sustentável. O ideal de sustentabilidade está destacado no contexto dos ODS, no sentido de que os objetivos estão voltados para a promoção das dimensões da sustentabilidade: dimensão social (objetivos 1; 2; 3; 4; 9; e 11); dimensão ambiental (objetivos 6; 12; 13; 14; e 15); dimensão econômica (objetivos 7; 8; e 10); dimensão ética (objetivo 5; e 17); e dimensão jurídico-política (objetivo 2; 3; 4; 11; e 16) (GOMES; FERREIRA, 2018, p. 171).
\end{abstract}

Muito se discutiu ao longo dos anos acerca das dimensões da sustentabilidade, por muito se defendeu o tripé da sustentabilidade, através das dimensões, social, econômica e ambiental, mas hoje em muito se critica a simplicidade dessa divisão, uma vez que a sustentabilidade é diretamente ligada a fatores culturais e políticos, tornando impossível dissociá-la desses.

Dessa forma, iremos trabalhar os conceitos das dimensões da sustentabilidade, afim de determinar os fatores essenciais para o seu exercício. Acerca da dimensão ambiental, Nascimento assevera:

\begin{abstract}
A primeira dimensão do desenvolvimento sustentável normalmente citada é a ambiental. Ela supõe que o modelo de produção e consumo seja compatível com a base material em que se assenta a economia, como subsistema do meio natural. Trata-se, portanto, de produzir e consumir de forma a garantir que os ecossistemas possam manter sua autorreparação ou capacidade de resiliência (NASCIMENTO, 2012, p. 55).
\end{abstract}

A dimensão ambiental está diretamente ligada a capacidade de recomposição do meio ambiente e a necessidade de deixá-lo retornar ao estado anterior para que possa ser novamente explorado. Representa a necessidade de mudança dos sistemas de produção e consumo vigentes, uma vez que o consumo exacerbado e o lucro voraz, fazem com que o meio

marinhos para o desenvolvimento sustentável. Objetivo 15. Proteger, recuperar e promover o uso sustentável dos ecossistemas terrestres, gerir de forma sustentável as florestas, combater a desertificação, deter e reverter a degradação da terra e deter a perda de biodiversidade. Objetivo 16. Promover sociedades pacíficas e inclusivas para o desenvolvimento sustentável, proporcionar o acesso à justiça para todos e construir instituições eficazes, responsáveis e inclusivas em todos os níveis. Objetivo 17. Fortalecer os meios de implementação e revitalizar a parceria global para o desenvolvimento sustentável. (ORGANIZAÇÃO DAS NAÇÕES UNIDAS NO BRASIL, p. $18-19$.

CONPEDI LAW REVIEW | EVENTO VIRTUAL | v. 6 | n. 1 | p. 01 - 18 | JAN - DEZ | 2020 


\title{
A INTEGRAÇÃO LAVOURA PECUÁRIA FLORESTA COMO ALTERNATIVA PARA O DESENVOLVIMENTO SUSTENTÁVEL NO AGRONEGÓCIO
}

ambiente seja explorado de maneira predatória, e muitas vezes definitiva, sem que exista a oportunidade de autorreparação ou resiliência.

Diretamente interligada aos meios de produção atuais, a dimensão econômica é essencial para que seja possível alcançar a sustentabilidade. Nesse sentido, Nascimento dispõe:

\begin{abstract}
A segunda dimensão, a econômica, supõe o aumento da eficiência da produção e do consumo com economia crescente de recursos naturais, com destaque para recursos permissivos como as fontes fósseis de energia e os recursos delicados e mal distribuídos, como a água e os minerais. Trata-se daquilo que alguns denominam como ecoeficiência, que supõe uma contínua inovação tecnológica que nos leve a sair do ciclo fóssil de energia (carvão, petróleo e gás) e a ampliar a desmaterialização da economia (NASCIMENTO, 2012, p. 55).
\end{abstract}

Em relação à dimensão econômica, é necessário destacar a expressão ecoeficiência, ou seja, produzir de uma forma em que seja possível preservar o meio ambiente e a sua capacidade de autorreparação e resiliência, e garantir o desenvolvimento econômico.

A justiça social, que decorre da terceira dimensão denominada "dimensão social", é um fator sem o qual não há que se falar em desenvolvimento sustentável, visto que o combate à pobreza e uma garantia do mínima para a existência digna são essenciais para a concretização de Direitos Humanos. Assim destaca Nascimento:

\begin{abstract}
A terceira e última dimensão é a social. Uma sociedade sustentável supõe que todos os cidadãos tenham o mínimo necessário para uma vida digna e que ninguém absorva bens, recursos naturais e energéticos que sejam prejudiciais a outros. Isso significa erradicar a pobreza e definir o padrão de desigualdade aceitável, delimitando limites mínimos e máximos de acesso a bens materiais. Em resumo, implantar a velha e desejável justiça social (NASCIMENTO, 2012, p. 56).
\end{abstract}

Ao se analisar as três dimensões do desenvolvimento sustentável, segue-se na linha apresentada por Nascimento bem como por Gomes e Ferreira, no sentido de que as três dimensões ignoram fatores que são intrínsecos a execução do desenvolvimento sustentável. Gomes e Ferreira dispõem acerca da dimensão ética da sustentabilidade:

A dimensão ética da sustentabilidade está diretamente voltada para a relação da justiça intergeracional, de modo que a coletividade da presente geração é responsável pela herança ambiental e social que serão passadas para as gerações futuras, num plexo de solidariedade e fraternidade de aceitação do ser humano enquanto pessoa e do meio ambiente enquanto natureza, responsável por gerir a vida de todos os seres vivos (GOMES, FERREIRA, 2017, p. 95). 
As presentes gerações devem se sentir responsáveis pela guarda do meio ambiente, de forma que ele esteja saudável para as próximas gerações. A dimensão ética deve ser internalizada e trabalhada socialmente e é básica quando nos referimos a educação ambiental. O ser humano deve se sentir intimamente responsável pela preservação e qualidade de vida no planeta, e só a partir da internalização de conceitos como como pertencimento, respeito, fraternidade e solidariedade, que será possível atingir a sustentabilidade.

A quinta e última dimensão trazida por Gomes e Ferreira (2017), é a dimensão jurídico política. Apesar de a dimensão jurídico política também ser tratada por Nascimento, como um fator indissociável da sustentabilidade, no sentido de que as decisões concernentes às políticas ambientais e de desenvolvimento sustentáveis passam necessariamente pelo fator político, Gomes e Ferreira, vão além do envolvimento político nas decisões ambientais. Acerca do tema asseveram:

\begin{abstract}
A dimensão jurídico-política visa a efetivar e desenvolver os direitos fundamentais das presentes e futuras gerações, com o objetivo de asseverar e reforçar o plexo de desenvolvimento consubstanciado na preservação e proteção ambiental, sem, contudo, perder de vista a promoção social, o respeito à dignidade humana $\mathrm{e}$ aos direitos humanos, a melhor e adequada distribuição da renda e os conceitos de origem ética, que são vertentes indissociáveis do conceito de sustentabilidade. Trata de uma determinação principiológica vinculante que visa ao aperfeiçoamento da tutela efetiva dos direitos fundamentais para que possam se materializar em bemestar para as presentes e futuras gerações, num prisma de proteção da vida em suas diferentes formas (GOMES, FERREIRA, 2017, p. 96).
\end{abstract}

A dimensão jurídico política é uma dimensão garantidora do mínimo para a efetivação da sustentabilidade. De forma que os limites sejam respeitados e garantidos para as presentes e futuras gerações através do Estado Democrático de Direito (GOMES, FERREIRA, 2017).

Mesmo com todos os acontecimentos que apontam para uma grave crise ambiental, os esforços mundiais no sentido de mudança do padrão de consumo e de adoção do desenvolvimento sustentável ainda não tomaram as proporções devidas, tendo em vista principalmente questões ligadas ao regime econômico vigente, que nos modelos atuais não condiz com a ideia de desenvolvimento sustentável. Conforme afirma Faladori:

A maioria das análises e propostas engloba a crise ambiental sob 03 (três) temáticas: a superpopulação, os recursos e os resíduos. Por sua vez, estes três grandes problemas podem ser compreendidos sob um denominador comum: os limites físicos externos com os quais a sociedade humana se defronta. [...] Os problemas 
ambientais da sociedade humana surgem como resultado da sua organização econômica e social, e que qualquer problema aparentemente externo se apresenta, primeiro, como um conflito no interior da sociedade humana. [...] No fim das contas, nas duas conferências de países em âmbito mundial e no informe encomendado fica claro que a preocupação manifesta se dá em torno de como reduzir os níveis de poluição, depredação e de pobreza e superpopulação, sem tocar na forma social de produção, ou seja, no capitalismo (FOLADORI, 2001, p. 101-109).

No Brasil uma das principais atividades econômicas é o agronegócio. Entretanto, a atividade é responsável pela degradação ambiental nos moldes em que é exercida nos dias de hoje, passando a ser um embaraço ao desenvolvimento sustentável brasileiro.

\section{PLANO AGRICULTURA DE BAIXA EMISSÃO DE CARBONO}

O agronegócio no Brasil é responsável por grande parte do PIB do país. Segundo dados do Centro de Estudos Avançados em Economia Aplicada (CEPEA/USP) em parceria com a Confederação da Agricultura e Pecuária do Brasil (CNA) e a FEALQ (Fundação de Estudos Agrários Luiz de Queiroz), em 2019, a soma de bens e serviços gerados no agronegócio chegou a 21,4\% do PIB brasileiro, apresentando um crescimento de $0,3 \%$ em relação ao resultado de 21,1\% em 2018 (CEPEA/USP, 2020).

Em contraponto a importância do setor para a economia do País, a atividade agropecuária é uma grande emissora de gases que contribuem para o efeito estufa:

A quinta versão da Plataforma SEEG mostra que o Brasil emitiu cerca de 2,3 bilhões de toneladas de $\mathrm{CO} 2$ equivalente $(\mathrm{GtCO} 2 \mathrm{e})$ em 2016. Apenas a agropecuária contribuiu diretamente com cerca de 30\% desse total (499 MtCO2e) (SEEG, 2017). As emissões causadas diretamente pela agropecuária se referem à produção animal e vegetal, ao uso de fertilizantes nitrogenados na agricultura, à disposição de dejetos animais, à decomposição de resíduos culturais e ao cultivo de organossolos (IMAFLORA, 2018, p. 9).

Segundo relatório elaborado pela Imaflora e pelo Observatório do Clima, a agropecuária gera $30 \%$ do total de emissões de gases que contribuem para o efeito estufa no Brasil. O desenvolvimento econômico, a tecnologia empregada no campo e a necessidade do aumento de produção de alimentos, intensificaram essa emissão pelo setor ao longo dos anos (IMAFLORA, 2018), conforme se observa no gráfico: 
Figura 1: Evolução das emissões brutas de $\mathrm{CO}_{2}$ e pela Agropecuária no Brasil

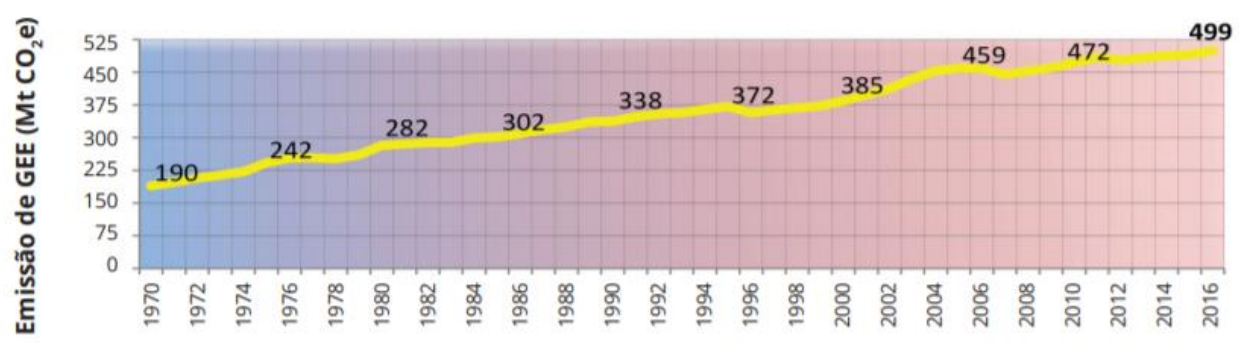

Fonte: IMAFLORA, 2018, p. 12

Entre os subsetores da agropecuária, alguns emitem mais gases de efeito estufa do que outros, como mostrar o gráfico a seguir:

Figura 3: Emissões de $\mathrm{CO}_{2}$ e por subsetor da agropecuária brasileira

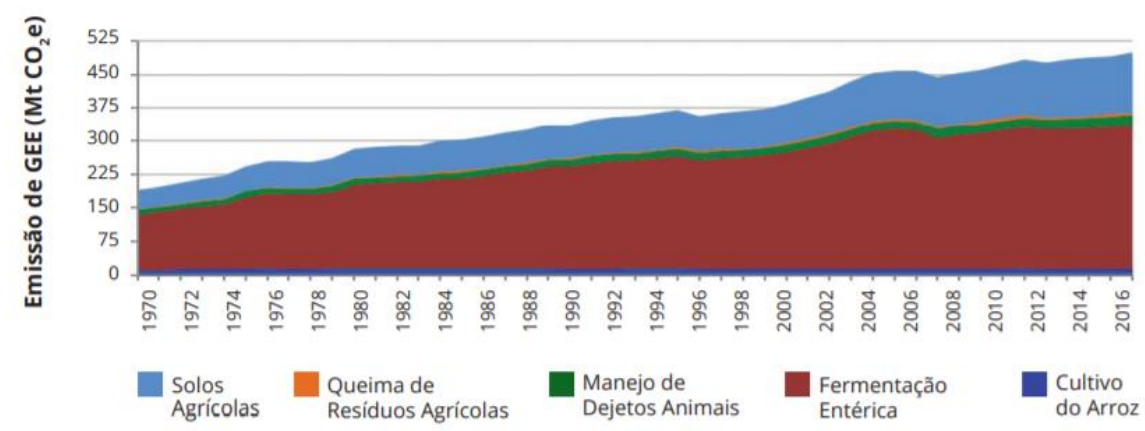

Fonte: IMAFLORA, 2018, p. 14

Segundo o relatório elaborado pela IMAFLORA, $86 \%$ das emissões do setor são provenientes da produção animal e o Brasil ocupa o $3^{\circ}$ lugar dos países que mais emite gases prejudiciais através das atividades agropecuárias (IMAFLORA, 2018, p. 14).

Seguindo a tendência mundial, o Brasil assinou um compromisso voluntário na COP 15, de redução entre $36,1 \%$ e $38,9 \%$ das emissões de gases que contribuem para o efeito estufa projetadas para 2020, estimando o volume de redução em torno de um bilhão de toneladas de CO2 equivalente (OBSERVATÓRIO ABC, 2013, p. 10). Para tanto: 
recuperação de pastagens atualmente degradadas; promover ativamente a integração lavoura-pecuária (iLP); ampliar o uso do Sistema Plantio Direto (SPD) e da Fixação Biológica de Nitrogênio (FBN); e Ampliar a eficiência energética, o uso de bicombustíveis, a oferta de hidrelétricas e de fontes alternativas de biomassa, de energia eólica e de pequenas centrais hidrelétricas, assim como ampliar o uso na siderurgia de carvão de florestas plantadas (BRASIL, 2012, p. 16).

Dessa forma, foi instituída a Política Nacional de Mudanças do Clima regulamentada hoje pelo Decreto n ${ }^{\circ}$ 9.578, de 22 de novembro de 2018. Para efeito deste decreto, no caso específico do da agricultura, ficou estabelecido no art. 17, inciso IV que fosse constituído o Plano Setorial de Mitigação e de Adaptação às Mudanças Climáticas para a Consolidação de uma Economia de Baixa Emissão de Carbono na Agricultura (plano ABC). Assim:

O Plano ABC, chamado de Plano da Agricultura de Baixa Emissão de Carbono, engloba compromissos referentes a seis processos tecnológicos e foi estruturado em sete programas 1) Recuperação de Pastagens Degradadas; 2) Integração LavouraPecuária-Floresta (iLPF) e Sistemas Agroflorestais (SAFs); 3) Sistema Plantio Direto (SPD); 4) Fixação Biológica do Nitrogênio (FBN); 5) Florestas Plantadas; 6) Tratamento de Dejetos Animais; e 7) Adaptação às Mudanças Climáticas (BRASIL, 2012, p. 20).

Para o presente trabalho iremos analisar o programa de Integração Lavoura Pecuária Floresta.

\section{INTEGRAÇÃO LAVOURA PECUÁRIA FLORESTA}

Dentro das propostas do Plano ABC, está a ILPF. Embora ainda não amplamente adotada, é conhecida mundialmente há muitos anos. "Há registros desse tipo de cultivo na Europa desde a antiguidade, com vários tipos de plantios associados entre culturas anuais e culturas perenes ou entre frutíferas e árvores madeireiras" (BALBINO et al, 2012, p. 03).

A ILPF busca consorciar a produção de alimentos com qualidade e quantidade através da conservação dos recursos naturais, objetivando a agricultura sustentável. Acerca do conceito de agricultura sustentável, Hardaker assevera:

É o manejo e conservação dos recursos naturais e a orientação de mudanças tecnológicas e institucionais que assegurem a satisfação das necessidades humanas para a presente e as futuras gerações. É uma agricultura que conserva o solo, a água e os recursos genéticos animais, vegetais e micro-organismos, não degrada o meio 
ambiente; é tecnicamente apropriada, economicamente viável e socialmente aceitável (HARDAKER, 1997, Item 2.1, tradução nossa) ${ }^{5}$.

Alinhada ao conceito de desenvolvimento sustentável, a agricultura sustentável demonstra, através do seu objetivo, ser promissora para alcançar o desenvolvimento sustentável mundial, uma vez que, tendo em vista o aumento da população mundial e a demanda por alimentos, não é possível paralisar a atividade agropecuária. Entretanto, por outro lado, caso a atividade continue se desenvolvendo nos moldes atuais, os danos ambientais serão irreversíveis e trarão consequências cada vez mais graves à população.

Dentro das possibilidades de se desenvolver a agricultura sustentável, a ILPF tem ganhado grande destaque. Nesse sentido, Balbino, Barcellos e Stone trazem sua conceitualização:

A ILPF é uma estratégia de produção sustentável, que integra atividades agrícolas, pecuárias e florestais, realizadas na mesma área, em cultivo consorciado, em sucessão ou rotacionado, e busca efeitos sinérgicos entre os componentes do agroecossistema, contemplando a adequação ambiental, a valorização do homem e a viabilidade econômica (BALBINO; BARCELLOS; STONE, 2011, p. 27).

Em relação a agricultura sustentável cabe destacar a técnica apropriada, a viabilidade econômica e a aceitabilidade social. Esses são fatores essenciais para a agricultura sustentável, encontrados na ILPF, desde que seja executada com seriedade:

A ILPF, desde que corretamente conduzida, é tecnicamente eficiente e ambientalmente adequada porque parte da premissa de ser implantada em áreas com condições edafoclimáticas favoráveis: solo corrigido; pluviometria adequada; temperatura e luz não limitantes; e água disponível em quantidade e qualidade adequadas. Além disso, preconiza a utilização de alguns princípios fundamentais: manejo e conservação do solo e da água; manejo integrado de insetos-praga, doenças e plantas daninhas; respeito à capacidade de uso da terra, ao zoneamento climático agrícola, e ao zoneamento agroecológico (ZAE); redução da pressão para abertura de novas áreas; diminuição da emissão de dióxido de carbono (CO2); sequestro de carbono; estímulo ao cumprimento da legislação ambiental, principalmente quanto à regularização das reservas legais(regeneração ou compensação)e das áreas de preservação permanente; dos serviços ambientais, adoção de boas práticas agropecuárias(BPA); certificação da produção; e ampliação positiva do balanço energético (BALBINO, BARCELLOS, STONE, 2011, p. 24).

\footnotetext{
5 Tradução livre de: “...the management and conservation of the natural resource base, and the orientation of technological and institutional change in such a manner as to ensure the attainment and continued satisfaction of human needs for present and future generations. Such sustainable development (in the agriculture, forestry and fisheries sectors) conserves land, water, plant and animal genetic resources, is environmentally nondegrading, technically appropriate, economically viable and socially acceptable" (HARDAKER, 1997, Item 2.1).
}

CONPEDI LAW REVIEW | EVENTO VIRTUAL | v. 6 | n. 1 | p. 01 - 18 | JAN - DEZ | 2020 
Nesse sentido há que se dizer que a ILPF está ligada diretamente aos pilares da agricultura sustentável, demonstrando viabilidade econômica, técnica apropriada e aceitabilidade social, uma vez que busca um equilíbrio entre o desenvolvimento econômico e a preservação do meio ambiente. Nesse sentido:

\begin{abstract}
Assim, a iLPF tem como principal objetivo a mudança do sistema de uso da terra, fundamentando-se na integração dos componentes do sistema produtivo, visando atingir patamares cada vez mais elevados de qualidade do produto, qualidade ambiental e competitividade. Portanto apresenta-se como uma estratégia para maximizar efeitos desejáveis no ambiente, aliando o aumento da produtividade com a conservação de recursos naturais no processo de intensificação de uso das áreas já desmatadas no Brasil (BALBINO; CORDEIRO; MARTINEZ, 2011, p. 1015).
\end{abstract}

A implantação do sistema de ILPF apresenta diversos benefícios, ambientais e econômicos, tais como o aumento da produtividade e qualidade do produto, além da mitigação da emissão de carbono na atmosfera e a recuperação dos solos e pastagens degradados.

Todavia, o sistema apresenta dificuldades quanto a sua implantação e por isso grande parte da área que pode ser utilizada para o cultivo no Brasil ainda não adotou o sistema. Dentre as dificuldades existentes, destaca-se a falta de conhecimento técnico por parte dos produtores rurais, a ausência de mão de obra capacitada, a falta de suporte e indisponibilidade de informações para a implementação do sistema tendo em vista a distância entre o centro de produção científica e tecnológica e o produtor rural. Além da falta de informação e acesso, cabe destacar a ausência de políticas públicas direcionadas ao ILPF e que efetivamente garantam o acesso ao crédito para a implementação do sistema (BALBINO; BARCELLOS; STONE, 2011, p. 110-112).

O estado que possui a maior área de cultivo por ILPF é o Mato Grosso do Sul, com aproximadamente 11,5 milhões de hectares. Todavia, o Rio Grande do Sul é um estado em que grande parte das áreas destinadas a agricultura utilizam-se de algum tipo de Integração, conforme se pode ver no gráfico abaixo: 


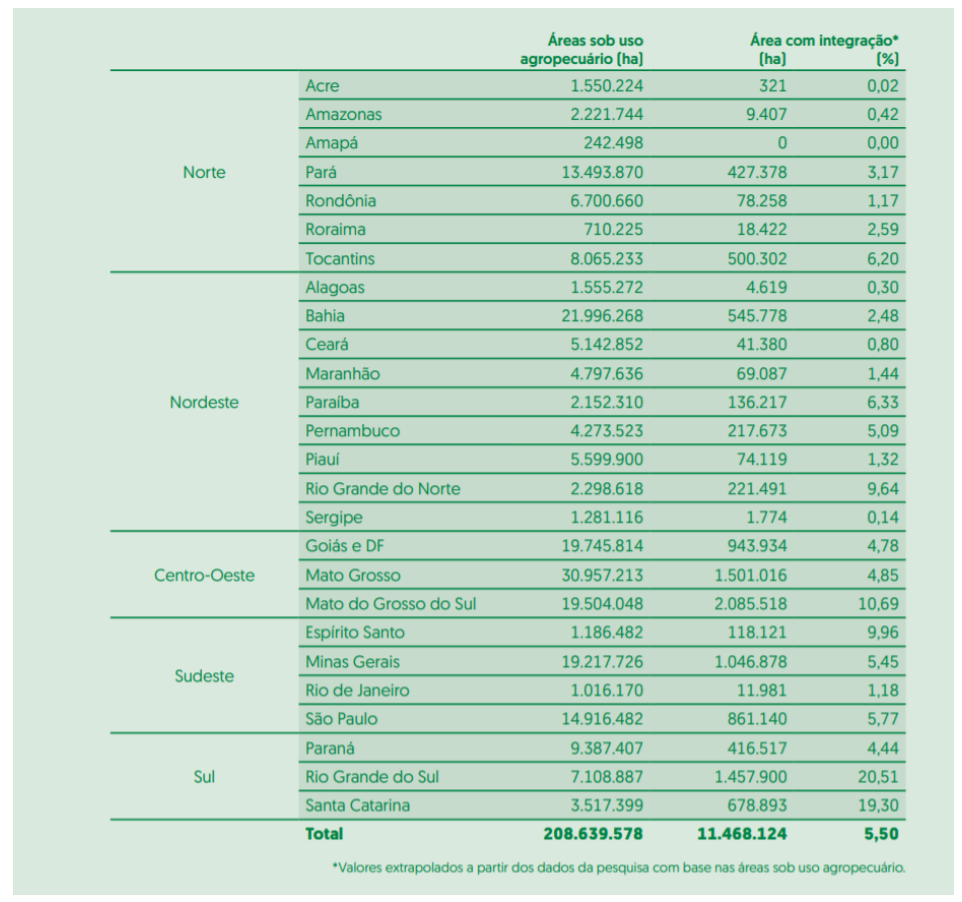

Fonte: EMBRAPA, 2016, p.05

Muitos questionamentos são realizados no que tange a falta de adoção do sistema, visto que faz parte do Plano ABC. Há previsão no plano sobre a concessões de linhas de crédito especiais para aqueles produtores que quiserem implantar o sistema, contudo, de acordo com o relatório emitido pelo Observatório ABC 2018/2019, observa-se que em 2016 e 2017, os produtores contrataram 63\% do montante disponibilizado para empréstimo. Em 2017 e 2018, 73\%, e em 2018 e 201919 81\% do total ofertado. Apesar do aumento do valor contratado, o número de contratos diminuiu significativamente, de 4.559 em 2016 para 3.123 em 2018 (OBSERVATÓRIO ABC, 2019, P.6). Dessa forma percebe-se que ainda não há uma adesão significativa por parte dos produtores.

A complexidade de execução da ILPF é um fator que assusta parte dos produtores rurais, bem como o alto custo para a implantação do sistema. Além disso, a falta de conhecimento e capacitação técnica por parte do produtor rural, bem como a burocracia excessiva, também são fatores que influenciam na não adesão da ILPF (IMAFLORA, 2018 p. 53). Dessa forma, é possível afirmar que não basta a disponibilização do crédito, por se tratar de um sistema de complexa implantação. Por isso, se faz necessário uma implementação de programas de capacitação em todo o país para que os produtores possam ter acesso a técnica e para que sejam competentes afim de capacitar a mão de obra. 
Por envolver três tipos diferentes de atividades, o ILPF demanda capacitação de mão de obra e maiores investimentos. Dessa forma, o poder público deve estar atento para as necessidades do produtor de modo a implementar uma política pública que seja realmente efetiva e passível de implementar uma mudança real, assim como é previsto no Plano ABC.

\section{CONSIDERAÇÕES FINAIS}

A crise ambiental, as mudanças climáticas e os desastres ambientais são responsáveis pela preocupação mundial quanto ao meio ambiente. Entretanto, ainda não habita totalmente na consciência popular a urgência dos cuidados com a preservação e recuperação do meio ambiente.

Paralela a discussão de preservação ambiental, o mundo segue em busca do desenvolvimento sustentável. No modelo econômico vigente, onde há uma busca pelo lucro voraz, a mudança de paradigma parece distante, mas aos poucos percebe-se uma alteração de comportamento. As empresas buscam, cada vez mais, se alinhar com os interesses ambientais.

Dessa forma, para que seja possível alcançar o desenvolvimento econômico alinhado a preservação ambiental, o desenvolvimento sustentável se faz totalmente necessário. No Brasil, a atividade agropecuária é responsável por grande parte da emissão de gases de efeito estufa e, consequentemente, pela degradação ambiental. Por isso, se faz necessária a análise deste mercado para que o Brasil comece a tomar medidas sobre conservação ambiental e a redução da emissão de gases que contribuem para o efeito estufa.

Após a implementação do Plano ABC, o Brasil consolidou a sua preocupação com a emissão de gases prejudiciais ao meio ambiente. Assim, em resposta aos problemas apresentados, dentro das estratégias previstas pelo Plano, há implementação da ILPF, que se mostrou como um interessante aliado na busca do desenvolvimento sustentável na pecuária, por apresentar ótimos resultados quanto a redução da emissão dos gases prejudiciais e a recuperação de pastagens degradadas. Todavia, a implementação do sistema apresenta desafios.

Apesar da existência de linhas de créditos destinadas àqueles produtores que desejam implementar o sistema, a falta de atratividade pelas taxas de juros, bem como a burocracia e a falta de transparência no processo, afastam os interessados. Além das dificuldades financeiras, tendo em vista o alto custo da implementação, o eventual endividamento dos produtores, bem como a falta de lucratividade das propriedades também contribui para o desinteresse. 
O emprego de técnicas diferenciadas para a integração, bem como a utilização dos três sistemas, são fatores que devem ser amplamente divulgados e ensinados, visto que a falta de informação e capacitação técnica são quesitos sem os quais não há a menor possibilidade de implantação do sistema.

Conclui-se que a ILPF é, de fato, um grande aliado ao alcance do desenvolvimento sustentável. Todavia, o Poder Público deve se empenhar no que tange a divulgação e capacitação de mão de obra. A transparência no processo de obtenção de empréstimos, bem como a desburocratização também se fazem necessários para que cada vez mais o Brasil caminhe em direção ao desenvolvimento sustentável no setor agropecuário.

\section{REFERÊNCIAS}

BALBINO, Luiz Carlos; et al. Agricultura sustentável por meio da integração lavourapecuária-floresta (ILPF). Informações agronômicas, 2012. Disponível em: http://www.ipni.net/PUBLICATION/IA-

BRASIL.NSF/0/67E9CCA96D48CF6685257A84004F5D7D/\$FILE/IA-2012-138.pdf.

Acesso em: 03 dez. 2019.

BALBINO, Luiz Carlos; BARCELlOS, Alexandre Oliveira; STONE, Luiz Fernando (Ed.). Marco referencial em integração Lavoura-Pecuária-Floresta (ILPF). Brasília, DF: Embrapa Informação Tecnológica, 2011. Disponível em: https://www.alice.cnptia.embrapa.br/bitstream/doc/923530/1/balbino01.pdf. Acesso em: 03 dez. 2019.

BALBINO, Luiz Carlos; CORDEIRO, Luiz Adriano Maia; MARTÍNEZ, Gladys Beatriz. Contribuições dos sistemas de integração lavoura-pecuária-floresta (iLPF) para uma agricultura de baixa emissão de carbono. Revista Brasileira de Geografia Física, Brasília, v. 4, n. 6, p. 1014-1026, nov. 2011. Disponível em: https://www.alice.cnptia.embrapa.br/handle/doc/921371. Acesso em: 03 dez. 2019.

BÖLTER, Serli Genz; DERANI, Cristiane. Direito ambiental e desenvolvimento sustentável: uma análise da judicialização das relações sociais. Revista Veredas do Direito, Belo Horizonte, v. 15, n. 33, p. 209-242, set./dez. 2018. Disponível em: http://dx.doi.org/10.18623/rvd.v15i33.1242. Acesso em: 23 mar. 2020.

BRASIL. Decreto $\mathrm{n}^{\circ}$ 9.578, de 22 de novembro de 2018. Consolida atos normativos editados pelo Poder Executivo federal que dispõem sobre o Fundo Nacional sobre Mudança do Clima, de que trata a Lei $\mathrm{n}^{\circ}$ 12.114, de 9 de dezembro de 2009, e a Política Nacional sobre Mudança do Clima, de que trata a Lei $\mathrm{n}^{\circ} 12.187$, de 29 de dezembro de 2009. Diário Oficial da União, Brasília, 22 nov. 2018. 
BRASIL. Ministério da Agricultura, Pecuária e Abastecimento. Plano setorial de mitigação e de adaptação às mudanças climáticas para a consolidação de uma economia de baixa emissão de carbono na agricultura: plano $A B C$ (Agricultura de Baixa Emissão de Carbono). Brasília: MAPA/ACS, 2012.

CEPEA. Centro de Estudos Avançados em economia aplicada. PIB do Agronegócio. CEPEA-USP/CNA/ESALQ. 2020. Disponível em: https://www.cepea.esalq.usp.br/br/pib-doagronegocio-brasileiro.aspx. Acesso em: 09 mar. 2020.

COMISSÃO MUNDIAL SOBRE MEIO AMBIENTE E DESENVOLVIMENTO. Nosso futuro comum. 2. ed. Rio de Janeiro: Fundação Getúlio Vargas, 1991.

EMBRAPA. ILPF em números. Brasília: Embrapa, 2016. Disponível em: https://www.embrapa.br/busca-de-publicacoes/-/publicacao/1064859/ilpf-em-numeros.

Acesso em: 09 mar. 2020.

FOLADORI, Guillermo. Limites do desenvolvimento sustentável. Tradução Marise Manoel. Campinas: Editora da UNICAMP/Imprensa Oficial, 2001.

GOMES, Magno Federici; FERREIRA, Leandro José. A dimensão jurídico-política da sustentabilidade e o direito fundamental à razoável duração do procedimento. Revista do Direito, Santa Cruz do Sul, n. 52, v. 2, p. 93-111, maio/set. 2017. Disponível em: http://dx.doi.org/10.17058/rdunisc.v2i52.8864. Acesso em: 23 mar. 2020.

GOMES, Magno Federici; FERREIRA, Leandro José. Políticas Públicas e os objetivos do desenvolvimento sustentável. Revista Direito e Desenvolvimento, João Pessoa, v. 9, no 2, p. 155-178, ago./dez. 2018. Disponível em: https://doi.org/10.25246/direitoedesenvolvimento.v9i2.667. Acesso em: 23 mar. 2020.

HARDAKER, J. Brian. Guidelines for the integration of sustainable agriculture and rural development into agricultural policies. FAO agricultural policy and economic development, Rome, series 4, 1997. Disponível em: http://www.fao.org/3/w7541e/w7541e00.htm\#Contents. Acesso em: 09 mar. 2020.

IMAFLORA. Emissões do Setor de Agropecuária, 2018. Disponível em: https://www.imaflora.org/biblioteca?page $=1 \&$ pesquisa=emiss $\%$ C3\%B5es+do+setor+de+agro pecu\%C3\%A1ria. Acesso em: 09 mar. 2020

LIMA. Magda Aparecida de; et al, Estoques de carbono e emissões de gases de efeito estufa na agropecuária brasileira. 3. ed. Brasília: Embrapa, 2015.

MACHADO, V. de F. A produção do discurso do desenvolvimento sustentável: de Estocolmo a Rio 92. 2005. Tese (Doutorado em Desenvolvimento Sustentável) - Centro de Desenvolvimento Sustentável, Universidade de Brasília, Brasília, 2005.

NASCIMENTO, Elimar Pinheiro do. Trajetória da sustentabilidade: do ambiental ao social, do social ao econômico. Estudos avançados, São Paulo, v. 26, n. 74, p. 51-64, out. 2012. 
OBSERVATÓRIO ABC. Agricultura de baixa emissão de carbono: a evolução de um novo paradigma. 2013. Disponível em: https://www.embrapa.br/busca-de-publicacoes//publicacao/959512/agricultura-de-baixa-emissao-de-carbono-a-evolucao-de-um-novoparadigma-sumario-executivo. Acesso em: 09 mar. 2020.

OBSERVATÓRIO ABC. Análise dos recursos do programa ABC: safras 2017/18 e 2018/19. Disponível em: http://observatorioabc.com.br/2019/11/analise-dos-recursos-doprograma-abc-safras-201718-e-201819/. Acesso em: 09 mar. 2020.

ONUBR, Nações Unidas no Brasil. Documentos Temáticos: Objetivos de Desenvolvimento Sustentável $\quad 1, \quad 2, \quad 3, \quad 5, \quad 9, \quad 14 . \quad$ Disponível em https://www.undp.org/content/dam/brazil/docs/publicacoes/documentos-tematicos-ods-072017.pdf. Acesso em: 23 de março de 2020.

ONUBR, Nações Unidas no Brasil. Transformando o Nosso Mundo: Agenda 2030 para o desenvolvimento sustentável. Disponível em: https://nacoesunidas.org/wpcontent/uploads/2015/10/agenda2030-pt-br.pdf. Acesso em: 23 mar. 2020. 